\title{
ELEMENTOS TEÓRICO-METODOLÓGICOS PARA ANÁLISE DOS MOVIMENTOS SOCIAIS À LUZ DE UMA ABORDAGEM MARXISTA
}

\section{THEORETICAL-METHODOLOGICAL ELEMENTS FOR THE ANALYSIS OF SOCIAL MOVEMENTS FROM A MARXIST APPROACH}

Gabriel Teles ${ }^{1}$

\begin{abstract}
Resumo
O presente trabalho busca trazer uma análise teórica acerca dos movimentos sociais ancorados em diversos autores marxistas ou inspirados no marxismo. Para tanto, busca-se evidenciar as contribuições de Marx para a análise dos movimentos sociais, o conceito de movimentos sociais na perspectiva marxista e, posteriormente, inseri-la, de forma esquemática, na dinâmica da sociedade (sua relação com as lutas de classe, desenvolvimento histórico da acumulação de capital, Estado, etc.). Busca, nesse sentido, demonstrar a fertilidade do marxismo para a compreensão e análise desse importante fenômeno da sociedade moderna. Palavras-chave: Movimentos Sociais; Marxismo; Luta de Classes; Lutas Sociais
\end{abstract}

\begin{abstract}
The present work brings a theoretical analysis about the social movements anchored in several Marxist authors or inspired in Marxism. In order to do so, it seeks to highlight Marx's contributions to the analysis of social movements, the concept of social movements in the Marxist perspective, and later to insert it schematically into the dynamics of society (its relation to class struggles, historical development of capital accumulation, state, etc.). It seeks, in this sense, to demonstrate the fertility of Marxism for the understanding and analysis of this important phenomenon of modern society.
\end{abstract}

Keywords: Social movements; Marxism; Class struggle; Social Struggles

\footnotetext{
${ }^{1}$ Doutorando em Sociologia pelo PPGS/USP, mestre em Sociologia pelo PPGS/UFG, graduado em Ciências Sociais/UFG. Pesquisador pelo Grupo de Pesquisa Dialética e Sociedade (GPDS) e Núcleo de Estudos e Pesquisa sobre Movimentos Sociais (NEMOS); possui experiência na área de Sociologia, atuando principalmente nos seguintes temas: sociologia dos intelectuais, materialismo histórico, sociologia da arte, método dialético, movimentos sociais e movimento estudantil.
} 


\section{INTRODUÇÃO}

Refletir e teorizar sobre os movimentos sociais não é uma tarefa simples. Tal constatação procede da complexidade e das múltiplas determinações que estão emaranhadas nesse fenômeno social concreto. Complexidade esta derivada da própria sociedade capitalista, que aprofunda seus conflitos, complexifica as lutas de classes e irradia essas lutas para os grupos sociais.

Destrinchar e realizar o processo analítico dos movimentos sociais é uma pretensão de diversos pesquisadores, com diversas abordagens diferentes e perspectivas distintas. Por esse ângulo é impossível falar tão somente em uma "interpretação" ou "explicação" dos movimentos sociais. O problema, no entanto, ainda se resguarda no próprio entendimento e explicação do que vem a ser um movimento social e na dificuldade do desenvolvimento de uma concepção acerca dos movimentos sociais em um universo conceitual articulado e que expresse a realidade concreta.

Gastou-se e ainda se gasta muita tinta em análises sobre esse fenômeno, mas pouco se teorizou sobre ele. Isto significa que grande parte da literatura sobre os movimentos sociais possui caráter descritivo, não conseguindo avançar no processo analítico e na explicação do tema estudado. É por isso que o procedimento mais comum é o que se denomina de empiricismo, uma percepção muito empobrecedora do real, onde a análise se dá a partir da aparência do fenômeno, isolando-o das suas demais determinações e não historicizando-a.

Esses elementos geram deficiências para chegarmos a um processo analítico satisfatório dos movimentos sociais. Mesmo as abordagens já consolidadas na esfera científica acerca deste assunto possuem fragilidades que, apesar de contribuir com alguns elementos, acabam corroborando com o ocultamento da própria realidade social.

O que há por trás de toda essa diversidade de abordagens distintas acerca dos movimentos sociais, entre outros elementos, é a perspectiva social e política da qual um pesquisador está partindo. Há uma luta em torno do que pode vir a ser o termo "movimento social". É o que Bakhtin (2009) chama de lutas de classe em torno do signo. Os fenômenos/seres existem independentemente da consciência que os seres humanos possuem sobre ele. Quando há a percepção desse fenômeno/ser, ou seja, quando há a sua consciência, então os definimos ou conceituamos a fim de expressar o que ele significa. Nesse sentido, o movimento social (ser) existe, independente da ideia que temos sobre ele (signo). No entanto, mais importante do que esse elemento é a possibilidade de termos uma falsa ideia sobre o ser - que é o que geralmente ocorre, já que as ideias dominantes são as ideias da classe dominante (MARX \& ENGELS, 2007). Em síntese, essa diversidade existente é caudatária, além de outras questões, das lutas de classes, onde 
a perspectiva de classe possui um papel importante. Daí deriva-se uma escolha tanto teórica (ou ideológica) quanto metodológica, que se torna um elemento fundamental.

Por esse ângulo, a perspectiva marxista, à luz de seus instrumentais teórico-metodológicos, se apresenta como uma frutífera abordagem para a explicação e análise dos movimentos sociais. A concepção marxista dos movimentos sociais se difere das demais abordagens por diversos elementos. Esta distinção se dá, fundamentalmente, pelo método marxista de análise (dialético) efetivar o processo analítico dos fenômenos a partir de sua inserção na totalidade das relações sociais. Isto significa dizer que os movimentos sociais não podem ser vistos de forma isoladas das outras determinações da sociedade.

As ferramentas analíticas do método dialético, sobretudo suas categorias, tais como totalidade, historicidade, determinação fundamental, especificidade histórica, relação etc., trazem um rico painel de possibilidades de análise da sociedade. Os movimentos sociais, constituídos no interior da sociedade, também não escapam da análise à luz deste método.

Nesse sentido, buscaremos no presente trabalho trazer uma análise teórica acerca dos movimentos sociais ancorados em diversos autores marxistas ou inspirados no marxismo. Para tanto, busca-se evidenciar as contribuições de Marx para a análise dos movimentos sociais, o conceito de movimentos sociais na perspectiva marxista e, posteriormente, inseri-la, de forma sintética, na dinâmica da sociedade (sua relação com as lutas de classe, desenvolvimento histórico da acumulação de capital, Estado, etc.).

\section{MARX E OS MOVIMENTOS SOCIAIS}

A primeira questão que devemos pontuar é o contexto em que Marx realizou a sua produção intelectual. Suas obras estão localizadas, temporalmente, no final da metade do século XIX e se estende até a década de 80 desse mesmo século. Assim, há uma impossibilidade em seu pensamento de tratar sobre fenômenos que surgiram posteriormente, apesar de trazer vários elementos para se pensar os fenômenos contemporâneos.

O que fica evidente aqui é que Marx não poderia refletir sobre os movimentos sociais já que eles só apareceram, de forma consolidada e desenvolvida, quase um século depois de sua morte. O máximo que se pode atestar é que, em sua época, os movimentos sociais começaram a se 
desenvolver de forma embrionária, tal como o movimento das mulheres (movimento feminino) e o movimento estudantil, mas ainda muito ligados aos movimentos de classe ${ }^{2}$.

Marx, no entanto, realizou alguns apontamentos sobre grupos sociais de sua época que, posteriormente, desenvolveram movimentos sociais. Este é o caso do grupo social das mulheres. Marx, ao analisar o material autobiográfico do francês Peucheut, descreve a situação social das mulheres daquela época, denunciando a especificidade do caráter opressivo que sofriam e a repressão sexual. Além disso, afirma o caráter destrutivo do capitalismo para além da exploração das classes trabalhadoras:

Em alguns trechos sobre o "suicídio", extraídos das "mémoires tirés desenvolvimento archives de la police etc., par Jaques Peucheut", darei um exemplo dessa crítica francesa [...], que ao mesmo tempo pode nos mostrar até que ponto a pretensão dos cidadãos filantropos está fundamentada na ideia de que se trata apenas de dar aos proletários um pouco de pão e educação, como se somente os trabalhadores definhassem sob as atuais condições sociais, ao passe que, para o restante da sociedade, o mundo tal como existe fosse o melhor dos mundos (MARX, 2006, p. 22).

Assim, Marx não pensava que somente o proletariado sofria com as mazelas das relações capitalistas - apesar de ser o enfoque de seus escritos, devido ao papel revolucionário desta classe social. Nesse sentido, podemos observar que Marx já prenunciava os conflitos em torno dos grupos sociais à medida que a sociedade e o modo de produção capitalista se desenvolviam. No entanto, este autor não viveu o suficiente para presenciar o desenvolvimento dos movimentos sociais.

Já que Marx não escreveu sobre os movimentos sociais, suas contribuições se estruturam a partir de sua concepção teórico-metodológica que fornecem instrumentos que nos auxiliam à refletir sobre esse fenômeno social. O desenvolvimento da teoria da história das sociedades no geral (materialismo histórico) pode nos auxiliar a pensar a historicidade dos movimentos sociais que, assim como determinados fenômenos, surgem em determinadas condições históricas (Estado, classes sociais etc.). Os movimentos sociais são um fenômeno específico da sociedade capitalista (e, especificamente, num determinado momento dele, já que não existem desde o seu início).

\footnotetext{
Para haver movimentos sociais é necessário que a divisão social do trabalho tenha se complexificado ao ponto de criar vários grupos sociais com interesses diferentes e o nível de desenvolvimento da consciência social esteja bastante elevado. Só existe um movimento social quando um grupo social realiza sua ação coletiva com uma regularidade e quando possui uma consciência coletiva. Essas pré-condições para a existência dos movimentos sociais só existem na sociedade capitalista. Por conseguinte, os movimentos sociais surgem com a sociedade capitalista e não existem nas sociedades pré-capitalistas (JENSEN, 2014, p. 134).
}

\footnotetext{
2 A distinção entre movimentos sociais e movimentos de classes será desenvolvida no subtópico "Movimentos Sociais e Lutas de Classe".
} 
A teoria do capitalismo, desenvolvida de forma mais acabada em O capital (MARX, 2013; 2014; 2017) também nos ajuda a pensar sobre as consequências da dinâmica e do desenvolvimento da acumulação de capital nos grupos sociais. Estes, devido às suas condições e insatisfações sociais, unem-se e mobilizam-se, possibilitando a emergência de determinados movimentos sociais. Algumas ramificações do movimento ecológico surgem para combater as consequências desenfreadas da reprodução ampliada de capital, sobretudo em um de seus aspectos mais predatórios: a destruição ambiental, via poluição, super acúmulo de lixo tóxico etc. As lutas de classe na produção entre o proletariado e a burguesia, ponto essencial da dinâmica classista da sociedade capitalista, também traz consequências na hegemonia dos movimentos sociais. Enfim, uma multiplicidade de consequências na produção, circulação e reprodução do capital que estão inseridas na obra de Marx que versa sobre o capitalismo.

Outra contribuição de Marx para a análise dos movimentos sociais é a questão metodológica. Marx elaborou o método dialético, uma ferramenta intelectual imprescindível para a análise da realidade. Apesar de não ter escrito uma obra sistemática sobre isso, é possível perceber, em sua obra, discussões acerca da construção deste método (MARX \& ENGELS, 1991; 1977; MARX, 1985, 1983, 1988).

Em síntese, o conjunto das contribuições de Marx nos auxilia na explicação sobre os movimentos sociais e sua dinâmica. A questão do método, na construção conceitual, é o ponto fundamental. É a partir do método dialético, à luz de suas categorias e da perspectiva do proletariado, que outros autores, depois de Marx, pensaram a questão dos movimentos sociais. É o que desenvolveremos no próximo subtópico.

\section{O CONCEITO DE MOVIMENTOS SOCIAIS}

Um dos elementos fundamentais para o marxismo, do ponto de vista metodológico, é a questão da unidade entre conceito e teoria. Portanto, apesar de começarmos pelo conceito, não significa que ele seja suficiente para analisar e entender os movimentos sociais. Um conceito está relacionado ao outro, constituindo um universo conceitual que, por sua vez, forma uma teoria. Por esse ângulo, começar pela questão conceitual significa delimitarmos o que entendemos por esse fenômeno social, para, posteriormente, inseri-lo na totalidade das relações sociais.

Nos manuais e nas grandes sínteses das abordagens dos movimentos sociais, há, geralmente, um tópico sobre a forma como o marxismo analisa este fenômeno. A ironia é que, não raro, o marxismo é inexistente nas pretensas abordagens marxistas dos movimentos sociais. $\mathrm{O}$ 
que geralmente aparecem são deformações da concepção marxista, retirando o seu caráter político ou caindo em análises insuficientes que não conseguem explicar o fenômeno e muito menos conceituá-lo.

Nesse sentido, poucos foram os autores que avançaram na conceituação na discussão em torno dos movimentos sociais na perspectiva marxista (TELES, 2017). Do nosso ponto de vista, dois autores contribuem, de forma fundamental, na conceituação dos movimentos sociais de maneira satisfatória e em coerência com o método dialético e o materialismo histórico. Estes são Karl Jensen e Nildo Viana. Em outro trabalho, colocamos:

O primeiro [Karl Jensen], no texto "Teses para os Movimentos Sociais", tem o mérito de colocar em discussão o ponto fundamental de qualquer movimento social: os grupos sociais. Este aspecto é o ponto de partida que irá guiar o autor na confecção das dez teses. Apesar disso, em Jensen, ainda não há um desenvolvimento de um conceito e concepção de movimentos sociais, mas tão-somente uma definição e a análise de alguns de seus aspectos que, inclusive, contribui para o avanço que há no livro "Os Movimentos Sociais" de Nildo Viana. Neste último, há um aprofundamento e desenvolvimento de uma teoria dos movimentos sociais, buscando desenvolver um universo conceitual que dê conta de explicar este fenômeno social (TELES, 2017, p. 69-70).

Karl Jensen (2014) definirá movimentos sociais como movimento de grupos sociais. A base de qualquer movimento são, evidentemente, seres humanos, reais e concretos; a especificidade dos movimentos sociais, então, recairia nos grupos sociais. O mérito de Jensen está em colocar o fundamental entre as determinações deste fenômeno (a base social), mas é insuficiente no sentido de não trazer outros elementos, além das motivações internas e externas, dos movimentos sociais. O seu limite consiste em não aprofundar os demais elementos constituintes dos movimentos sociais, além de não desenvolver a sua definição de movimentos sociais ${ }^{3}$.

Este será um dos pontos de partida para Nildo Viana (2016) desenvolver seu conceito de movimentos sociais. Para este autor, em concordância com Jensen, a base social dos movimentos sociais são os grupos sociais ${ }^{4}$. No entanto, há outros elementos que são importantes para que esta base social gere um movimento social.

Assim, os movimentos sociais, para Viana, são conceituados como "mobilização (ações coletivas ou compartilhadas) de determinados grupos sociais derivadas de certas situações sociais que geram insatisfação social, senso de pertencimento e determinados objetivos" (VIANA, 2016, p. 43). Aqui há um desenvolvimento conceitual, não presente em Jensen, acerca dos outros

\footnotetext{
${ }^{3}$ É compreensível este nível rudimentar de análise feita por Jensen, posto que a forma de estruturação do seu breve trabalho é a partir de teses. Isto significa que não se trata de uma obra desenvolvida e fundamentada. Isto pode trazer algumas elucidações acerca dos seus limites e problemas de análise.

4 "Um movimento só é social se este possuir seres humanos, reais e concretos, que efetivam o deslocamento (social). A importância do grupo social se dá justamente por evidenciar o tipo específico de agrupamento humano que realiza este deslocamento" (TELES, 2017, p. 71).
} 
elementos dos movimentos sociais. Elementos necessários para que os grupos sociais criem e desenvolvam um movimento. Mas, antes de discuti-los, é necessário aprofundar a discussão da base social dos movimentos sociais.

O que são grupo sociais? Há várias formas de entender um grupo social: desde as formulações das representações cotidianas ("senso comum") até as formulações mais estruturadas e acabadas de algumas abordagens teóricas/ideológicas. Dentre estas últimas formulações há, por exemplo, as considerações realizadas por Lapassade (1989). Todavia, este autor iguala "grupos sociais" com "grupos organizados". Jensen e Viana, por sua vez, concordam em relação ao entendimento acerca deste fenômeno: na concepção destes autores, grupos sociais referem-se a um determinado conjunto de pessoas que possuem algo em comum. Um exemplo, fornecido por Jensen, nos auxiliará a elucidar esta questão:

Tomemos um exemplo: o movimento das mulheres. Este é o grupo social que lhe movimenta. Este conjunto de pessoas, este grupo social, possui em comum o fato de todos os seus membros pertencerem ao sexo feminino. Esta é a motivação interna do movimento. Entretanto, o simples fato de pertencer ao sexo feminino não cria nenhum movimento social, pois somente no interior de determinadas relações sociais é que pertencer ao sexo feminino cria a necessidade de ação coletiva. Essas relações sociais certamente se baseiam na opressão do sexo feminino e é esta a motivação externa deste movimento social. O mesmo ocorre com o movimento negro: o simples fato de pertencer à raça negra não é motivo suficiente para surgir um movimento social, mas, quando a raça negra se vê oprimida, então surge a sua necessidade. Um movimento social só existe quando o conjunto de pessoas que o compõe possuem aspectos comuns, que podem ser tanto biológicos (raça, sexo) quanto culturais e ideológicos (projeto político) (JENSEN, 2014, p. 48, itálicos nossos).

Jensen, no trecho acima, evidencia o aspecto em comum entre os indivíduos que forma um grupo social. No entanto, com este grau de generalidade, não é possível captar a especificidade dos grupos sociais, já que nesta definição podemos colocar categorias profissionais, grupos de interesse etc. É por isso que Viana (2016) aponta que um grupo social é um conjunto de indivíduos que compartilham determinadas semelhanças que podem ser derivadas de três aspectos: corporeidade, situação e cultura. "Assim, entre outros exemplos possíveis, podemos dizer que os negros e as mulheres se enquadram no primeiro grupo [corporeidade], enquanto os jovens e estudantes, entre outros, no segundo grupo [situação] e os religiosos e ecologistas, entre outros, no terceiro [cultura]" (VIANA, 2016, p. 27).

Estas três condições se desdobram em três variedades de grupos sociais: os grupos orgânicos, situacionais e culturais. De forma sintética, os grupos sociais orgânicos, cuja unidade se respalda na corporeidade, são baseados em seus aspectos biológicos ou em sua condição física. Já os grupos situacionais se estruturam, como o nome já diz, em uma determinada situação social, 
como os estudantes, por exemplo. Ou seja, neste caso, diferentemente dos grupos orgânicos, é a situação social que desenvolve um grupo social e não o inverso. Por fim, os grupos culturais constituem seu arranjo grupal em torno de doutrinas, crenças etc. - pacifistas e ecologistas integram este grupo.

Cada grupo social, portanto, pode constituir um movimento social específico; o primeiro é a base social do segundo. Contudo, como já colocamos anteriormente, apenas a existência do grupo social não gera um movimento social. Os grupos sociais só produzem um movimento a partir de uma determinação situação social.

\begin{abstract}
A existência de um grupo social e o pertencimento dos indivíduos a ele geram uma condição de possibilidade, ou uma precondição, mas é necessário algo externo que faz com que tal grupo tenha alguma necessidade de gerar um movimento. Essa "motivação externa" é a situação social [...] no exemplo do movimento negro, o fato de indivíduos possuírem as mesmas características fenotípicas e, por conseguinte, pertencerem ao mesmo grupo social, não gera um movimento social. Se as relações entre as raças fossem igualitárias, então não haveria motivo para mobilização. No entanto, se as relações raciais são marcadas pela opressão, discriminação, segregação, então temos uma situação social que tende a gerar um movimento social deste grupo. [...] A situação social é fundamental para explicar os movimentos sociais, pois é ela que faz surgir determinado grupo social ou então que ele tenha necessidade de agir e lutar. Claro que a criação de um grupo social não é suficiente para ele gerar um movimento social, pois dependendo das relações sociais concretas e do grau de conformismo, isso pode não ocorrer. Além da existência do grupo social, é necessário que a existência de uma situação social especiffica, que é marcada por opressão, necessidades não atendidas, descontentamento com a sociedade ou aspectos dela, difusão de ideologias ou doutrinas que geram inimigos imaginários ou alvos de ódio ou ressentimento, etc. (VIANA, 2016, p. 31-33, itálicos do autor).
\end{abstract}

Jensen (2014, p. 130), em outras palavras, também trata desta questão:

Os grupos sociais se movimentam por motivos internos e, ao mesmo tempo, externos.
Isto ocorre porque um grupo social só existe no interior de uma relação social e por isso
o seu movimento é provocado por suas necessidades próprias produzidas no interior de
sua relação com o conjunto da sociedade.

Por esse ângulo, os grupos sociais buscam gerar um movimento social quando possuem uma situação social específica. Mas isso ainda é insuficiente para formar um movimento social. $\mathrm{Na}$ conceituação de Viana há mais quatro determinações complementares que são indispensáveis para constituir um movimento social: a insatisfação social, o senso de pertencimento, a mobilização e o objetivo.

A insatisfação social é derivada da situação social. A falta de estrutura sanitária, degradação do meio ambiente, falta de moradias etc. são situações que podem gerar uma insatisfação no interior dos grupos sociais. Mas a percepção desta insatisfação pelos grupos sociais pode ser justa ou não. Por isso que a insatisfação social pode ser, além de uma resposta à injustiça, à destruição, à opressão 
etc., "uma moeda de troca, busca de vantagens e privilégios, ou manutenção dos mesmos, ou, ainda delírios e desequilíbrios psíquicos" (VIANA, 2016, p. 34). Este aspecto, por sua vez, é deveras negligenciado nas análises dos movimentos sociais. Há uma ideia idílica acerca dos movimentos sociais, como se suas mobilizações buscassem sempre uma causa justa, relacionados ao bem-estar dos grupos sociais que lhe dão origem etc., mas isto não corresponde com a realidade.

O segundo elemento complementar para a constituição de um movimento social é o senso depertencimento. Um grupo social, com uma determinada insatisfação derivada de sua situação social específica, sem a consciência coletiva desta insatisfação, não fornece elementos suficientes para a geração de um movimento. Um indivíduo isolado, insatisfeito com alguma situação que lhe transtorna, não terá elementos para se mobilizar de forma coletiva. É nesse sentido que o senso de pertencimento expressa o reconhecimento que o ensejo da insatisfação social não é uma questão meramente individual, e sim coletiva. É a partir desse senso de pertencimento que os grupos sociais, baseados em suas situações e insatisfações sociais, mobilizam-se em torno de um ou mais objetivos.

A terceira determinação, então, é a mobilização. No caso dos movimentos sociais é uma mobilização grupal, que pode ser tanto uma ação coletiva, quanto uma ação compartilhada.

\begin{abstract}
Uma ação coletiva é a que é realizada por um conjunto de pessoas reunidas fisicamente ou integradas através de terminadas concepções (doutrina, plano de ação, projeto político, etc.) e uma ação compartilhada é aquela na qual pode ser realizada por indivíduos isoladamente, mas compartilhando coempções ou práticas a partir de um senso de pertencimento. [...] Um indivíduo participa de um movimento social quando ele se reúne com outras para efetivar determinadas ações ou quando ele, isoladamente, realiza ações que são realizadas por outros do mesmo grupo (que pertence ou que apoia) e com as mesmas motivações/objetivos e ele faz isso com consciência desse processo (VIANA, 2016, p. 38).
\end{abstract}

Nesse sentido, uma mobilização só tem sua razão de existência se esta busca atingir determinados objetivos. O objetivo no interior dos movimentos sociais é a meta cujo movimento almeja concretizar com finalidades de resolver o problema da situação em que se encontra (BERGER, 2015).

Estes são os elementos definidores e as determinações essenciais do conceito de movimentos sociais. Retomemos, pois, a conceituação de Nildo Viana (2016), a qual temos acordo, e buscamos utilizá-la na presente pesquisa: os movimentos sociais são mobilizações, que podem ser tanto ações coletivas quanto compartilhadas, de determinados grupos sociais derivadas de certas situações sociais que geram insatisfação social, senso de pertencimento e determinados objetivos. 
Antes de concluirmos essa discussão é preciso pontuar um último elemento que tangencia o conceito de movimentos sociais: as suas ramificações. A existência destas pressupõem que os movimentos sociais não são homogêneos. No interior de um movimento social específico, como o movimento negro, existem diversas divisões e objetivos.

Uma determinada parte do movimento negro pode reivindicar igualdade entre as raças, outras a supremacia do negro diante das outras raças, ou, especificamente, microreformismos e vantagens na sociedade capitalista. Apesar de todas essas reivindicações serem de um mesmo grupo social, ela se destoa do ponto de vista da consciência e da organização de como superar (ou dissimular) uma determinada situação social. É nessa perspectiva que podemos falar em ramificações nos movimentos sociais (TELES, 2017, p. 75).

Nildo Viana utiliza a metáfora do caule para visualizar melhor essa questão. Um movimento social seria um caule em que brotam diversas ramificações. "Essa metáfora ajuda a entender o conceito de ramificação no sentido que aqui o utilizamos, significando derivações dos movimentos sociais, sendo partes deles sem ser a sua totalidade ou ele mesmo" (VIANA, 2016, p. 40, itálico nosso). Assim, um movimento social pode gerar organizações mobilizadores, subgrupos, representações, ideologias, manifestações etc. Entre as ramificações, as organizações mobilizadoras são as que mais ganham destaque nas análises devido à sua importância na dinâmica dos movimentos sociais.

Em síntese, estas considerações conceituais nos auxiliam a pensar, analiticamente, os movimentos sociais. Viana, bem como outros autores, vem contribuindo com o desenvolvimento e aprofundamentos de alguns elementos aqui colocados, no que tange a questão conceitual. Tratase de uma rica agenda teórica a ser aprofundada que permite o desabrochamento de análises, à luz do método dialético, dos movimentos sociais.

O itinerário do presente subtópico teve como objetivo evidenciar o conceito de movimentos sociais. Trata-se de um aspecto fundamental para efetivar o processo analítico deste fenômeno. No entanto, é necessário sair do abstrato e chegar ao concreto. Em nosso contexto, isso significa inserir os movimentos sociais na dinâmica da sociedade. Devido ao espaço, focalizaremos, brevemente, os aspectos que acreditamos serem fundamentais: as lutas de classes, o desenvolvimento histórico do capitalismo e o Estado.

\section{MOVIMENTOS SOCIAIS E LUTA DE CLASSES}

O motor da história, já diziam Marx e Engels, é a luta de classes (MARX \& ENGELS, 1988). Por esse ângulo, as classes sociais possuem um papel fundamental no interior da dinâmica 
da sociedade. Assim, é necessário indagar: qual a diferença entre classes sociais (a base dos movimentos de classe) e grupos sociais (a base social dos movimentos sociais)? Como já definimos o que compreendemos por grupos sociais, é necessário explicitar, brevemente, o que entendemos por classes sociais.

Não se trata de pensar classes sociais a partir da ideologia da estratificação social (STAVENHAGEN, 1979) onde há a criação de modelos pré-fabricados a partir da renda (ou de qualquer outra "variante") que se aplicam à realidade, sem vínculo nenhum com a realidade concreta. Compreendemos aqui classes sociais no sentido marxista, isto é, como um conjunto de indivíduos que possuem um determinado modo de vida, interesses e lutas em comum contra outras classes sociais a partir de uma determinada atividade estabelecida na divisão social do trabalho, derivada pelo modo de produção dominante (MARX, 2010; MARX, 1986; MARX \& ENGELS, 1992; VIANA, 2012).

Assim definido, torna-se mais claro a diferença entre ambos os fenômenos.

[...] As classes sociais diferem dos grupos sociais que estão na base dos movimentos sociais porque são geradas social e historicamente (ao contrário dos grupos orgânicos) e possuir interesses comuns (o que nem sempre ocorre nos grupos sociais), além de que nem sempre tais grupos também efetivam lutas em comum contra outras classes (ou grupos). Contudo, o elemento fundamental é que a sua delimitação ocorre via divisão social do trabalho no sentido mais geral do termo. [...] As classes sociais são conjuntos de indivíduos submetidos à divisão social do trabalho na sociedade e é isso que gera um modo de vida comum, interesses comuns e luta comum contra outras classes sociais. Os grupos situacionais, que são os grupos sociais citados que mais podem ser confundidos com as classes sociais, são ou subdivisões destas ou produtos transitórios ou determinados por local de moradia, demandas sociais, situação social, etc. (VIANA, 2016, p. 52-53).

Nesse sentido, se é certo que o arranjo social dos movimentos sociais são os grupos sociais, então a sua composição social é, também, uma composição de classes. Um exemplo poderá clarificar melhor esta questão: no interior de um mesmo grupo social, como o das mulheres, podemos vislumbrar diversas manifestações de classe e subdivisões desta. Há mulheres com pertencimento burguês, proletária, intelectual, camponesa, burocrata etc. Isto significa dizer que os grupos sociais não são homogêneos, e o que os diferencia, essencialmente, é a questão de classe. Os interesses de uma mulher proletária são distintos de uma mulher burguesa, gerando diferença (caso se juntem ou formem um movimento social) no tipo de insatisfação, senso de pertencimento, forma de mobilização, objetivos etc.

Assim, os movimentos sociais são uma resposta da luta de classes na sociedade capitalista, podendo ser monoclassistas (formados tão somente por uma classe social) ou policlassistas 
(formados por duas ou mais classes socais). O exemplo do grupo das mulheres pode ser considerado um exemplo de movimento policlassista.

Com estas considerações, já podemos avançar na discussão, o que remete a necessidade de analisar a composição de classe dos movimentos sociais (e suas ramificações), bem como a sua hegemonia interna. A determinação fundamental, neste aspecto, é o pertencimento de classe.

Esta questão se desdobra na necessidade de perceber as variedades dos movimentos sociais, já que eles não são homogêneos. É nesse sentido que podemos falar em três variedades deste fenômeno: os movimentos sociais conservadores, reformistas e revolucionários.

Os movimentos sociais conservadores são majoritariamente monoclassistas e manifestam a hegemonia burguesa no seu interior. $O$ foco de suas mobilizações insurge para a reprodução da sociedade capitalista, reforçando seus elementos constituintes em articulação com os objetivos e insatisfações grupais que os mobilizam. Um exemplo desta variedade seria o movimento racista. Suas características principais são a intolerância e a aloctonia (aversão ao alóctone, ou seja, ao diferente).

Já os movimentos sociais reformistas são prevalentemente policlassistas e é a variedade com o maior número de indivíduos mobilizados. Fundamentalmente sua hegemonia é burguesa. Porém, em determinados contextos, a burocracia pode conseguir sua hegemonia. A principal característica desta variedade é a sua ação endereçada ao Estado e a dinâmica institucional, podendo oscilar ora enquanto colaboração, ora quanto em oposição, dependendo de sua composição de classe no interior de suas ramificações. Os conceitos que nos auxiliam a pensar esta variedade de movimento social são os de reivindicação ${ }^{5}$ e Estado.

Devido ao grande número de movimentos sociais reformistas, ela se desdobra em tendências: conservadores, reformistas e revolucionárias. Em outro momento, resumimos estas diferenças:

\begin{abstract}
A tendência conservadora expressa a hegemonia burguesa dentro dessa variedade a partir, sobretudo, de grupos orgânicos que expressam um aloctonismo e autoctonismo exacerbado devido ao ressentimento provocado por determinados tipos de opressão, criando um maniqueísmo. [...] A tendência reformista abraça os elementos definidores dessa variedade específica de movimento social, constituindo a reivindicação endereçada ao Estado como seu objetivo maior. Por fim, a tendência revolucionária é, quase sempre dissidente e minoritária nos movimentos sociais reformistas. A vigência cultural (hegemonia) predominante é a proletária. Devido ao seu posicionamento, essa tendência possui uma maior volatilidade e muitas vezes abandona sua posição revolucionária. Suas ações não são endereçadas ao Estado e nem para grupos alóctones, mas sim ao
\end{abstract}

\footnotetext{
${ }^{5}$ A reivindicação se posta em uma determinada insatisfação específica de cada movimento social. Se o movimento estudantil, por exemplo, se mobiliza devido a precarização da assistência estudantil, então sua reinvindicação será a partir desta base de insatisfação e endereçada à burocracia universitária.
} 
proletariado (como classe) e para a hegemonia proletária (contribuindo para a luta cultural desta classe) (TELES, 2017, p. 77-78).

Finalmente, os movimentos sociais revolucionários são quase inexistentes, devido à hegemonia burguesa. Suas características são as mesmas da tendência revolucionária dos movimentos sociais reformistas, mas sem suas ambiguidades.

Em síntese, a importância da variedade dos movimentos sócias é perceber a composição de classe de cada movimento social específico, bem como a hegemonia em seu interior. Trata-se de apontamentos gerais sobre os movimentos sociais, mas que elucidam acerca dos movimentos sociais específicos, tal como o movimento estudantil, movimento negro, etc.

\section{MOVIMENTOS SOCIAIS, CAPITALISMO E ESTADO}

O nosso itinerário até aqui apontou para a conceituação dos movimentos sociais e, posteriormente, a sua inserção na dinâmica das lutas de classe. Resta-nos evidenciar a relação entre os movimentos sociais e capitalismo, bem como a sua principal forma de regularização, o Estado.

Com a tendência de reprodução ampliada do capital, como bem explica Marx em O Capital, as relações mercantis fluem para além das relações de produção capitalista, invadindo relações sociais até então não exploradas pelo capital. A mercantilização e a burocratização, oriundas dos desdobramentos deste fenômeno, são os elementos que atingem diretamente os movimentos sociais. Comecemos pela mercantilização.

A mercantilização é o processo "pelo qual a produção capitalista de mercadorias vai se expandindo e subsumindo as formas de produção não-capitalistas e as formas sociais, incluindo o Estado" (VIANA, 2016, p. 88). Assim, os movimentos sociais necessitam de recursos financeiros para efetuar suas mobilizações; a forma, quantidade e importância desses recursos dependerão do movimento social em questão, de suas ramificações, tendências, contexto histórico etc.

Derivada desta discussão, podemos elencar dois aspectos da mercantilização que atingem os movimentos sociais: as ondas e as escalas de mercantilização. O primeiro acompanha o desenvolvimento histórico do capitalismo, ou seja, está atrelado a um determinado regime de acumulação de capital. Trata-se da forma como a mercantilização se manifesta historicamente no interior do capitalismo, o que traz consequências para os movimentos sociais. Já as escalas de mercantilização, elemento mais importante da mercantilização relacionadas aos movimentos sociais, estão relacionadas à da questão do impacto do processo mercantil na dinâmica dos movimentos sociais. Podemos falar em escala mínima, média e máxima. 
$\mathrm{Na}$ sociedade capitalista, ninguém escapa da necessidade de dinheiro para comprar e adquirir mercadorias ou mercancias. Nesse sentido, mesmo que de forma mínima, os movimentos sociais e suas ramificações necessitam de dinheiro, tanto para a compra de um mero cartaz até a necessidade da compra de um navio para realizar suas mobilizações marítimas (tal como o Greenpeace, uma organização mobilizadora do movimento ecológico).

$\mathrm{Na}$ escala mínima, os recursos financeiros são ainda limitados e não criam impacto no movimento e em suas ações. Geralmente é feita a partir de arrecadações, venda de ingressos em festividades, doação tanto dos integrantes quanto dos apoiadores etc. $\mathrm{Na}$ escala média, os recursos financeiros tornam-se uma necessidade. Normalmente a ramificação dos movimentos sociais que mais são atingidas pela escala média são as organizações mobilizadoras. Uma determinada organização mobilizadora pressupõe um conjunto de elementos mais estruturados que lhe constrange buscar uma maior arrecadação de recursos financeiros, tanto para os gastos com a organização quanto para a mobilização. A escala máxima de mercantilização, por sua vez, já é sintomática de que o movimento social, ou sua ramificação, já está se autonomizando e perdendo o seu caráter de movimento. Se a escala máxima de mercantilização estiver ao lado do maior grau de burocratização, então há a cristalização de uma organização burocrática, e não mais um movimento social, mesmo que este ainda se declare enquanto tal.

Ainda sobre essa questão, é necessário colocar que não só os movimentos sociais e suas ramificações que são atingidas pela mercantilização, mas igualmente os seus indivíduos. Uma pessoa pode ingressar em um determinado movimento com objetivos de tirar vantagens no interior deste movimento. Assim, esta questão se complexifica ainda mais.

As ondas e escalas de mercantilização atingirão as variedades dos movimentos sociais (conservadores, reformistas, revolucionários) de formas distintas, de acordo com a hegemonia no seu interior.

Ao lado da mercantilização existe o processo da burocratização ${ }^{6}$. É por isso que a discussão acerca do Estado, a principal forma de regularização da sociedade capitalista, torna-se importante. Se é certo, como bem diz Marx (1988), que o Estado é uma associação da classe dominante para fazer valer seus interesses de classe, então não podemos percebê-lo enquanto uma "entidade" neutra, que serve a todos e todas da mesma forma.

Nesse sentido, o Estado capitalista é a principal forma de regularização da sociedade capitalista, sendo inclusive, para alguns, derivadas do próprio modo de produção capitalista

\footnotetext{
${ }^{6}$ Há também a questão da competição social, oriunda da mentalidade burguesa. Mas devido ao espaço, não poderemos desenvolver essa questão aqui, mas ela estará presente em nossa discussão ao longo da pesquisa.
} 
(MATHIAS \& SALAMA, 1983). Sua especificidade se dá por ser uma relação de dominação mediada pela burocracia.

Há duas formas de entender relação entre Estado e movimentos sociais. A primeira é a ação do Estado endereçado os movimentos sociais e a segunda é a ação dos movimentos sociais endereçados ao Estado. Comecemos pela primeira.

Enquanto principal forma de regulação da sociedade, os seus tentáculos estão envoltos em quase todos os fenômenos sociais. Assim, o Estado executa o processo de regularização dos movimentos sociais. Além disso, no caso das organizações mobilizadoras, elas se submetem à legislação vigente de um determinado país, o que pressupõe controle, impostos e a necessidade de formalização. Os principais meios que o aparato estatal atua nos movimentos sociais são a partir da cooptação, burocratização e repressão.

A cooptação pode ser direta ou indireta. A primeira, realizada pelo próprio aparato estatal, é efetivada quando ocorre um determinado financiamento do Estado sob os movimentos sociais, assim como cargos e outras vantagens para os indivíduos ou coletividade de indivíduos. Já a cooptação indireta se dá a partir de instituições ou subterfúgios legais que ofuscam a visibilidade do processo de cooptação ${ }^{7}$. As políticas estatais ${ }^{8}$, dependendo de seus elementos, também podem ser caracterizadas como uma determinada cooptação indireta. No entanto, é necessário observar que as políticas estatais mudam de acordo com o desenvolvimento do capitalismo, ou seja, a partir de cada mudança nos regimes de acumulação. Isto significa que as políticas estatais, em cada período de desenvolvimento da acumulação, assumem a forma de ordenamento.

Um outro meio de relação entre Estado e movimentos sociais é a burocratização. Tal fenômeno é entendido aqui como a constituição e/ou ampliação de organizações burocráticas e, por consequência, da intensificação do controle social. À medida que um movimento cresce e necessita de recursos financeiros, igualmente cresce a necessidade de sua formalização, heterogestão e demais aspectos que contribuem para a burocratização.

As próprias exigências legais para reconhecimento jurídica, elemento necessário para algumas atividades (além do financiamento), é outro elemento incentivador de burocratização. Outra forma de incentivar a burocratização é através dos regimentos internos de suas instituições, que geram exigências organizacionais, tal como no caso das instituições de ensino (universidades, escolas), que criam regras formais e burocratizantes para a existência de organizações estudantis (VIANA, 2016, p. 105).

\footnotetext{
7 Um exemplo do primeiro tipo de cooptação seriam as lideranças de algumas organizações mobilizadoras de movimentos sociais que são elencados para assumir cargos dentro do aparato estatal, conseguindo, assim benefícios próprios. Exemplo do segundo seria empresas ou instituições estatais que financiam movimentos sociais via editais, concursos, etc.” (TELES, 2017, p. 82).

8 Chamadas também de "políticas públicas".
} 
A análise concreta da burocratização nos movimentos sociais pode ser percebida a partir da sucessão de regimes de acumulação. Assim, podemos falar em ondas de burocratização.

Enfim, a última relação entre o Estado e os movimentos sociais é a repressão, entendida aqui como o aparato repressivo, tais como o exército, política, milícias etc., utilizado e instrumentalizado para combater os movimentos sociais. A repressão pode ser tanto seletiva quanto generalizada. A seletiva é aquela utilizada em casos específicos, atingindo sobretudo, os movimentos conhecidos como populares e as tendências mais radicais e contestadoras dos movimentos sociais. A repressão generalizada é aquela cuja ação se dá na totalidade da sociedade. Geralmente o seu uso é utilizado em determinados contextos históricos, tais como uma crise de legitimidade da democracia burguesa, que pode culminar em uma ditadura militar, governos fascistas etc.

O aparato estatal também pode tomar uma atitude de omissão perante os movimentos sociais. Geralmente a omissão do Estado é feita para os movimentos sociais conservadores, não interferindo (mesmo podendo existir uma legislação específica que o faça interferir) na mobilização desta variedade de movimento social.

Resta-nos, enfim, estabelecer a ação dos movimentos sociais endereçada ao Estado. Há duas orientações dos movimentos sociais para o aparato estatal: a orientação estatista e a civilista (VIANA, 2016).

A orientação estatista expressa uma relação orgânica e direta com o Estado, se vinculando a ele a partir de três perspectivas distintas: a composicionista (foco e objetivo em reformas legislativas, políticas estatais etc.), a utilitarista (que almeja e busca recursos financeiros), e a partidarista (realizado por setores aparelhados). Já a orientação civilista não possui o objetivo de constituir um vínculo com o Estado, podendo assumir tanto uma forma externalista (sem contato com o Estado), independente (o contato com o Estado é feito, mas não criando um vínculo) e a antiestatista (onde ocorre o confronto com o aparato estatal).

Em síntese, estes são os elementos que acreditamos ser basilares para qualquer análise dos movimentos sociais e sua relação com a totalidade da sociedade. É certo que há outras determinações, tais como a relação entre os movimentos sociais e a sociedade civil, cultura e demais aspectos da sociedade. No entanto, devido ao espaço, apontamos aqueles que possuem impacto maior no interior dos movimentos sociais e contribuirão para a análise proposta. 


\section{CONSIDERAÇÕES FINAIS}

O presente trabalho buscou analisar uma proposta teórica, ancorada no marxismo, que possibilitasse a compreensão e explicação dos movimentos sociais na sociedade capitalista. Por esse ângulo, a mobilização tanto dos principais conceitos desenvolvidos pelo marxismo quanto o seu método de análise da realidade social, o método dialético, mostraram-se oportunas ferramentas de investigação e exame que desvelam a condição essencial e existencial dos movimentos sociais. Trata-se, pois, não apenas de uma agenda de pesquisa a ser utilizada na análise concretas desses movimentos, mas também um importante instrumento político que pode vir a contribuir para as lutas sociais postas pelos mais diversos grupos sociais que compõe o complexo e multifacetado universo dos movimentos sociais.

\section{REFERÊNCIAS BIBLIOGRÁFICAS}

BAKHTIN, M. (VOLOCHINOV, V.). Marxismo e Filosofia da Linguagem. Trad. Michel Lahud e Yara Frateschi Vieira. São Paulo: Hucitec, 2009.

BERGER, Patrick. Movimentos Sociais, Futuro e Utopia. Revista Marxismo e Autogestão, v.02, n.03, 2015.

JENSEN, Karl. Teses Sobre os Movimentos Sociais. Marxismo e Autogestão. Ano 01, num. 01, jan./jun. de 2014.

LAPASSADE, G. Grupos, organizações e instituições. $3^{a}$ Ed. Rio de Janeiro: Francisco Alves, 1989.

MARX, Karl \& ENGELS, Friedrich. A Ideologia Alemã (Feuerbach). $8^{\circ}$ Edição, São Paulo, Hucitec, 1991.

MARX, Karl \& ENGELS, Friedrich. A Ideologia Alemã. São Paulo: Boitempo, 2007.

MARX, Karl \& ENGELS, Friedrich. Cartas Filosóficas e o Manifesto Comunista de 1848. São Paulo, Moraes, 1977.

MARX, Karl \& ENGELS, Friedrich. Manifesto do Partido Comunista. Petrópolis: Vozes, 1988.

MARX, Karl. A Miséria da Filosofia. São Paulo, Global, 1985.

MARX, Karl. Contribuição à Crítica da Economia Política. São Paulo, Martins Fontes, 1983.

MARX, Karl. O Capital. 5 Vols, $3^{\circ}$ edição, São Paulo: Nova Cultural, 1988.

MARX, Karl. O Capital. Livro I. São Paulo: Boitempo, 2013. 
MARX, Karl. O Capital. Livro II. São Paulo: Boitempo, 2014.

MARX, Karl. O Capital. Livro III. São Paulo: Boitempo, 2017.

MARX, Karl. O Suicídio. São Paulo: Boitempo, 2006.

MATHIAS, Gilberto \& SALAMA, Pierre. O Estado Superdesenvolvido. São Paulo: Brasiliense, 1983.

STAVENGANHEN, Rodolfo. Classes Rurais na Sociedade Agrícola. São Paulo: Edições Loyola, 1979.

TELES, Gabriel. Para uma análise marxista dos movimentos sociais: contribuições de Karl Jensen e Nildo Viana. Revista Despierta, Ano 04, n.04, 2017.

VIANA, Nildo. A teoria das classes sociais em Karl Marx. Florianópolis: Bookess, 2012.

VIANA, Nildo. Os Movimentos Sociais. Curitiba: Prismas, 2016. 